\title{
GESTIÓN DEL CAMBIO Y TRANSFORMACIÓN CULTURAL
}

En este mundo tan competitivo, el cambio es lo más frecuente en nuestras organizaciones. Los ejecutivos que tenemos la responsabilidad de incorporar cambios sabemos que la gestión de éste no es solo adoptar una nueva herramienta, proceso, modelo o estructura, con el propósito de alinearlas a la estrategia de la compañía en pos de reforzar nuestra ventaja competitiva y de mantener nuestra posición en el mercado Jimenez, A. (2013).

Todo cambio va más allá de su "adopción".Todo cambio, efectivamente, debe acompañarse de una transformación cultural de nuestros equipos Jimenez, A. (2013). Debemos lograr que las personas que nos acompañan hagan propia esta transformación y que, a partir de la fecha, la lleven en su ADN. Ahora, ¿cómo logramos que la lleven en su ADN? Esto no es una tarea tan fácil para los ejecutivos porque el personal suele sentir que las propuestas de mejora vienen de la "alta dirección" , que son imposiciones que alterarán su status quo o que generarán modificaciones que podrían complicarles la vida. Martinez, M., (2012)

¿Cómo hacer que nuestros equipos de trabajo se apropien del cambio? Una forma es comenzar por hacerlos participar en el análisis y en las alternativas propuestas. Así, ellos sentirán que las mejoras nacen del equipo y que no son impuestas Kotter. J et al. (2001). En segundo lugar, identifiquemos al líder nato del equipo, que no necesariamente es el líder formal. Esta persona será nuestro movilizador del cambio, encargándose de predicar y de convencer a sus compañeros de que los cambios tendrán un efecto positivo en nuestros clientes y, en consecuencia, en los resultados de la compañía. En tercer lugar, para hacer que nuestros equipos de trabajo se apropien del cambio debemos ser parte del cambio. El alineamiento del líder formal es de suma importancia. Desde el más alto nivel directivo hasta las líneas medias, se ha de mostrar que estos cambios son importantes para todos Kotter J. et al. (2001). Debemos predicar con el ejemplo y demostrar que todos estamos convencidos del cambio y que somos parte de él.

¿Cómo ayudamos para que la transformación cultural suceda? De modo adicional a lo antes descrito, debemos contar con expertos que nos acompañen con talleres reflexivos y motivacionales para afianzar el compromiso de toda la organización, lo que permitirá que el cambio sea exitoso.

Antes de cerrar mi comentario, basado en la experiencia, considero relevante agregar lo siguiente: la gestión del cambio no se refiere a cómo un empleado adopta un nuevo sistema, proceso, modelo o estructura, sino a cómo hace suyo dicho cambio, es decira cómo lo hace parte de su ADN. Por ejemplo, en el caso de un CRM (i.e., administración de las relaciones con el cliente), no es cómo los colaboradores utilizan con suma habilidad el nuevo sistema o conocen todas sus funcionalidades, sino la manera en que estas personas saben transformar el conocimiento de la nueva herramienta para lograr la máxima satisfacción de su cliente, lo cual reditará posteriormente en mejores resultados para la compañía Kotter J. et al. (2001). 


\section{Referencias:}

Kotter, J., et al. (2001). Gestión del cambio - Harvard Business Review. Bilbao, España: Ediciones Deusto, S.A.

Jimenez, A., (2013). Gestión del cambio. Madrid, España: Edición Díaz Santos.

Martinez, M., (2012). Gestión del cambio. Madrid, España: Ediciones Díaz de Santos. 